LICENÇA CC BY:

Artigo distribuído sob os termos

Creative Commons, permite uso e distribuição irrestrita em qualquer meio desde que $o$ autor credite a fonte original.

\title{
RACIONALIDADE INSTRUMENTAL E FORMAÇÃO HUMANA: UMA ANÁLISE A PARTIR DA TEORIA DO CAPITAL HUMANO
}

INSTRUMENTAL RATIONALITY AND HUMAN TRAINING: AN ANALYSIS FROM THE PERSPECTIVE OF THEORY OF HUMAN CAPITAL LA RACIONALIDAD INSTRUMENTAL Y FORMACIÓN HUMANA: UN ANÁLISIS A PARTIR DE LA TEORÍA DEL CAPITAL HUMANO

Gilmar Pereira da Silva ${ }^{1}$

Elido Santiago da Silva²

${ }^{1}$ Doutor em Educação pela UFRN. Docente do Programa de Pós-Graduação em Educação da Universidade Federal do Pará (UFPA), Belém, PA, Brasil.

${ }^{2}$ Doutor em Educação pela UFPA. Docente do Curso de Pedagogia da Universidade Federal do Piauí (UFPI), Parnaíba, PI, Brasil.

Resumo: O presente artigo tem como objetivo caracterizar os currículos dos cursos do ensino médio integrado à educação profissional a partir da racionalidade intrumental manifesta na proposta de formação humana. Tal proposição cumpriu-se por meio da análise dos projetos pedagógicos dos cursos de ensino médio integrado à educação profissional e do projeto pedagógico do Instituto Federal de Ciência e Tecnologia do Piauí - Campus Parnaíba. Destaca-se como referencial teórico os conceitos de Racionalidade Instrumental (SERVA, 1997; GUERREIRO RAMOS, 1981); Teoria do Capital Humano (SCHULTZ, 1973); Economia da Educação (CARNOY, 2006). Com a análise, chegou-se à delimitação de três categorias: "o mercado e seus serviços"; "a política pública de desenvolvimento"; e "o empreendedorismo e a formação humana instrumental". Como achado da pesquisa, destaca-se que a escola é um intenso movimento de assimilação e resistência frente ao projeto capitalista de formação humana e, no Instituto pesquisado, a racionalidade instrumental se manifesta nos documentos oficiais, tencionando a formação humana para um padrão de reprodução dos mecanismos de adaptação do processo educativo que de uma forma tende a uma formação parcializada pelo próprio projeto do capital.

Palavras-chave: Teoria do Capital Humano; Racionalidade instrumental; Formação humana.

Abstract: This study aims to characterize the curricula of Brazilian secondary school courses integrated with professional education, from the perspective of instrumental rationality. We analyzed these courses, as well as the pedagogical projects of the Science and Technology Federal Institute of Piauí - Parnaíba Campus. The theoretical framework was based on the concepts of Instrumental Rationality (SERVA, 1997; GUERREIRO RAMOS, 1981); the Theory of Human Capital (SCHULTZ, 1973); and Economics of Education (CARNOY, 2006). This analysis enabled us to outline three categories: "the market and its services"; "public development policy"; and, "entrepreneurship and human instrumental training". Our findings suggest that the school represents an intense movement of assimilation and resistance to the human training 
capitalist project, and, in the abovementioned Institute, instrumental rationality is shown in the official documents, which project human training to a reproduction pattern of the adaptation mechanisms of the educational process, which tends to lead to a training that is biased by the Capital project itself.

Keywords: Theory of Human Capital; Instrumental rationality; Human Training.

Resumen: El presente artículo tiene como objetivo caracterizar los currículos de los cursos de la secundaria integrados a la educación profesional a partir de la racionalidad instrumental manifiesta en la propuesta de formación humana. Tal proposición se ha cumplido a través del análisis de los proyectos pedagógicos de los cursos de la secundaria integrados a la educación profesional y de proyecto pedagógico del Instituto Federal de Ciencia y Tecnología de Piauí - Campus Parnaíba. Se señala como referencial teórico los conceptos de Racionalidad Instrumental (SERVA, 1997; GUERREIRO RAMOS, 1981); Teoría del Capital Humano (SCHULTZ, 1973); Economía de la Educación (CARNOY, 2006). Con el análisis, se logró la delimitación de tres categorías: "El mercado y sus servicios"; "la política pública de desarrollo"; y, "la iniciativa empresarial y formación humana instrumental". Como encontrado en la investigación, se señala que la escuela es un intenso movimiento de asimilación y resistencia frente al proyecto capitalista de formación humana y, en el Instituto investigado, la racionalidad instrumental se manifiesta en los documentos oficiales planteando la formación humana para un padrón de reproducción de los mecanismos de adaptación del proceso educativo que, de una forma, tiende a una formación parcializada por el propio proyecto del Capital.

Palabras-clave: Teoría del capital Humano; Racionalidad instrumental; Formación humana.

\section{Introdução}

Este artigo parte da proposta fundamental de caracterizar os currículos dos cursos do ensino médio integrado à educação profissional a partir da racionalidade intrumental manifesta na proposta de formação humana. Para isso descreveremos as análises dos projetos pedagógicos dos cursos de ensino médio integrado à educação profissional e do projeto pedagógico do Instituto Federal de Ciência e Tecnologia do Piauí - Campus Parnaíba, vigentes no ano de 2017.

Para o tratamento dos dados coletados, apoiamo-nos em um contínuo de racionalidades proposto por Maurício Serva (1997), baseado no pensamento original de Alberto Guerreiro Ramos (1981). Nesta matriz, definimos uma categoria a priori, sendo essa a formação humana instrumental. Para operacionalizar a análise, elaboramos o quadro referencial com as características fundantes da racionalidade da formação humana instrumental (Quadro 01). Destacamos que o presente texto está organizado em duas seções, sendo: Teoria do Capital Humano: fundamentos para uma Economia da Educação Instrumental; e A Formação Humana Instrumental.

Devemos, primeiramente, resgatar que, o conceito básico de racionalidade instrumental está vinculado ao arcabouço ideológico que sustenta o desenvolvimento do sistema capitalista desde sua origem até os dias atuais. Trata-se de um movimento 
que institui uma ação calculista às vivências do homem em sociedade, tornando-o um empreendedor que busca calcular os riscos e as recompensas de cada ação desprendida.

Para a análise, baseamo-nos em elencar elementos presentes nos projetos pedagógicos dos cursos de ensino médio integrado à educação profissional e do projeto pedagógico do Instituto Federal de Ciência e Tecnologia do Piauí - Campus Parnaíba, a partir do quadro referencial a seguir.

Quadro 01 - Racionalidade da formação humana instrumental

\begin{tabular}{|l|}
\hline Racionalidade da formação humana instrumental \\
\hline Cálculo - projeção utilitária das consequências \\
dos atos humanos; \\
\hline Fins - metas de natureza técnica, econômica ou \\
política (aumento de poder); \\
\hline Maximização dos recursos - busca da eficiência \\
máxima, sem questionamento ético, no tratamento \\
de recursos disponíveis, quer sejam humanos, \\
materiais, financeiros, técnicos, energéticos ou, \\
ainda, de tempo; \\
\hline Exito, resultados - o alcance, em si mesmo, de \\
padrões, níveis, estágios, situações, que são \\
considerados como vitoriosos face a processos \\
competitivos numa sociedade capitalista; \\
\hline Desempenho - performance individual elevada na \\
realização de atividades, centrada na utilidade; \\
\hline Utilidade - dimensão econômica considerada na \\
base das interações como um valor generalizado; \\
\hline Rentabilidade - medida de retorno econômico dos \\
êxitos e dos resultados esperados; \\
\hline Estratégia interpessoal - aqui entendida como \\
influência planejada sobre outrem, a partir da \\
antecipação das reações prováveis desse outrem \\
a determinados estímulos e ações, visando atingir \\
seus pontos fracos. \\
\hline
\end{tabular}

Fonte: Serva (1997, p.22.).

Por isso, entendemos que a racionalidade instrumental serviu como base para estruturar a organização escolar do capitalismo, visto que a modernidade elencou esta razão para reorganizar as relações científicas e, assim, imprimir nova dinâmica à própria sociedade. Motta (2003, p. 100), atento a essa dinâmica, afirma que 
A hegemonia da razão instrumental pressupõe a desvalorização do pensamento ético e da ação afetiva. A ciência substitui o pensamento não utilitário. Essa ciência está primordialmente colocada a serviço da produção. A lógica da produção, paulatinamente, subordina a educação, a política, o lazer.

Ao subordinar a organização escolar do capital, a racionalidade instrumental aumenta o potencial de inferências calculistas que podem ser desenvolvidas no interior dessas unidades educacionais. Percebemos o processo de avaliação da aprendizagem como um dos maiores reprodutores da lógica instrumental. Alunos estudam e são recompensados pelo escore de acertos que obtêm nas avaliações ou nos trabalhos escolares, transformando o ato de aprender em um processo econômico, em que recursos são potencializados ou economizados dependendo do resultado obtido. Guerreiro Ramos (1981. p. 22), observando o processo de justificação dos mecanismos de exploração a serem reproduzidos pela ciência, afirma que:

\footnotetext{
Deve ser dito que, a fim de salvar o que na moderna ciência social é correto, é necessário compreender o caráter precário de seus principais pressupostos, a saber, que o ser humano não é senão uma criatura capaz do cálculo utilitário de consequências e o mercado o modelo de acordo com o qual a sua vida associada deveria organizar-se. Na verdade, a ciência social moderna foi articulada com o propósito de liberar o mercado das peias que, através da história da humanidade e até o advento da revolução comercial e industrial, o mantiveram dentro de limites definidos.
}

A liberdade que o capital precisava para direcionar um processo de exploração que o isentasse de culpa pelos insucessos de grande parcela da classe trabalhadora em obter a parcela devida de ganhos por seu trabalho foi ofertada pela Teoria do Capital Humano (SCHULTZ, 1973). Uma economia da educação baseada no esforço do indivíduo em se adaptar e se diferenciar o suficiente para se tornar atraente ao mercado é uma miragem perfeita para a fase flexível do capitalismo contemporâneo descrita por Sennett (2009) como sendo um período no qual se exige do trabalhador uma maior capacidade de adaptação às novas formas de produção. Desta maneira, precisamos clarificar, na seção seguinte, os elementos da Teoria do Capital Humano que fundamentam a Economia da Educação instrumental.

\section{Teoria do Capital Humano: fundamentos para uma Economia da Educação Instrumental}

"[...] Esse impulso absoluto de enriquecimento, essa caça apaixonada ao valor é comum ao capitalista e ao entesourador, mas, enquanto o entesourador é apenas o capitalista ensandecido, o capitalista é o entesourador racional" (MARX, 2013. p.229). Ao começar com esta citação de Karl Marx, marcamos a principal característica da modernidade e do desenvolvimento do capitalismo. Buscando a explicação racional para o crescimento econômico, um dos ganhadores do Prêmio de Ciências Econômicas em memória de Alfred Nobel no ano de 1979, em estudos patrocinados por "generosa dotação da Ford Foundation", atentou para a diversidade de repertórios, que são adquiridos por meio da experiência ou via instrução formal, que um indivíduo pode acumular e que são utilizados de forma instrumental para o aumento de ganhos financeiros. 
Theodore W. Schultz (1902-1998) isolou o fator educacional como explicador do crescimento econômico e tornando-o preditor para modelos que avaliavam o desenvolvimento de países e regiões do capitalismo central a partir dos anos 1950. Segundo Schultz (1973. p.13), "Uma abordagem de investimento, estou convencido disto, é necessária para pensar-se sobre o crescimento econômico"

Schultz (1973) defende que a educação possui valor econômico, uma vez que: "se baseia na ideia de que as pessoas têm que potencializar suas capacidades como produtoras e consumidoras, mediante o investimento nelas mesmas e a escolarização é o investimento em capital humano mais importante" (SCHULTZ, 1973, p. 10-11).

Ao tratar a educação como investimento, Schultz cria e reproduz um esquema racional que prevê que todo esforço deve ser avaliado previamente para que os possíveis resultados sejam mensurados e a ação real seja afirmada ou negada. Cria-se, assim, uma teoria de motivação a partir da expectativa dos resultados que o incremento do grau de educação pode ocasionar a seu investidor. Schultz (1973) afirma que a educação é o maior investimento em capital humano. Entretanto, tal investimento foi negligenciado pela economia clássica que buscava na concentração de capital financeiro o real fator de explicação para o desenvolvimento econômico.

A análise de dados de crescimento feitos pela equipe e por colaboradores do trabalho de Schultz mostrou, segundo seu viés, que houve um crescimento durante os anos de 1950 e 1960 que não estavam vinculados com o aumento da produção industrial ou pelo aumento do capital ou bens de produção. Afirma ele que,

Nesse ínterim, durante a década passada, houve importantes progressos no pensamento econômico quanto ao investimento no capital humano. Esta faixa de investimentos é classificada da seguinte maneira: escolaridade e educação de nível mais alto, treinamento realizado no local do emprego, migração, saúde e informação econômica (SCHULTZ, 1973. p. 17).

Portanto, para completar sua tese que a economia clássica negligenciava variáveis que não estavam ligadas aos incrementos de capital ou bens de produção, Schultz, durante os estudos feitos na década de 1960 e que culminaram com sua obra no início da década de 1970, incluiu em sua análise variáveis que estavam relacionadas com o desenvolvimento do sistema escolar, com as correntes migratórias e com os serviços de assistência social e de saúde para assim montar sua equação que valorizaria o fator humano no crescimento econômico.

A análise de desenvolvimento de economias devastadas por duas guerras em menos de meio século, por meio de investimentos no sistema escolar, das correntes migratórias e dos serviços de assistência social e de saúde recorreu em analisar os meios de perpetuação do capitalismo. Samuel Bowles e Herbert Gintis (2014. p. 221) afirmam que,

O capitalismo é um sistema no qual os meios de produção pertencem e são controlados por uma pequena minoria. A massa de indivíduos, longe do controle dos recursos produtivos, é forçada a vender sua força de trabalho para viver. A escolarização, a formação ocupacional, a educação infantil e a assistência à saúde cumprem uma dupla função econômica: eles desempenham um papel essencial na produção, embora indiretamente, e também são essenciais para a perpetuação de toda a ordem econômica e social (tradução nossa). 
A própria reprodução do capitalismo necessita do investimento em educação, mesmo que esse investimento seja baseado em dois projetos distintos de formação e que configure e ajuste a dualidade estrutural cara ao capital. O projeto de educação daqueles que são os detentores dos meios de produção é mais rico em sentido do que aquele que serve aos vendedores da própria força de trabalho. O repertório cultural disponível para os detentores dos meios de produção é possibilitado pelo empobrecimento da classe que vive do trabalho, estabelecendo um processo de concentração e centralização do capital, no qual os capitalistas se apropriam de uma parcela significativa do produto do trabalho da classe que não possui os meios de produção (MARX, 2013).

Entretanto, Schultz (1973, p. 31) caminhou com sua tese sem atentar para a crítica da economia capitalista e afirmou que,

Embora seja óbvio que as pessoas adquiram capacidades úteis e conhecimentos, não é óbvio que essas capacidades e esses conhecimentos sejam uma forma de capital, que esse capital seja, em parte substancial, um produto do investimento deliberado, que tem-se desenvolvido no seio das sociedades ocidentais a um índice muito mais rápido do que o capital convencional (não-humano), e que o seu crescimento pode muito bem ser a característica mais singular do sistema econômico.

Na tentativa de "flexibilizar" o conceito de capital, Schultz iguala o detentor da força de trabalho a uma mercadoria, visto que, como elemento fundamental do capital, "A circulação de mercadorias é o ponto de partida do capital. Produção de mercadorias e circulação desenvolvida de mercadorias - o comércio - formam os pressupostos históricos a partir dos quais o capital emerge" (MARX, 2013. p.223). Assim, o trabalhador passa de produtor de mercadoria a se oferecer no mercado de trabalho como portador de capital humano. Torna-se, pois, a própria mercadoria que será disputada por possíveis compradores que, neste caso, são os próprios capitalistas.

Portanto, a produção de valor a partir da educação, preferencialmente formal, garante ao portador elementos que tenderão a diferenciá-lo dos demais membros da classe trabalhadora. Assim, a elaboração de um esquema racional que justificasse a necessidade do processo de diferenciação da mão de obra, mesmo que entendida por Smith (2010) como processo natural do capitalismo moderno, tomou um curso de explicação para o estágio de desenvolvimento de determinada região.

Destarte, a Economia da Educação, como campo científico, fundou-se nas proposições dos economistas clássicos, arquitetando estabelecer uma relação causal entre o aumento da produtividade de determinada empresa ou o crescimento econômico de um certo país ao coeficiente de escolaridade da mão de obra empregada pela empresa ou dos anos de estudo dos cidadãos do certo país.

Os economistas podem buscar investigar o fenômeno educativo a partir de três fatores, segundo Carnoy (2006): primeiramente, massivo investimento feito por governos e contribuintes precisa ter um efeito positivo: os custos de estruturação e manutenção de sistemas de ensino públicos são elevados, sendo que os recursos que sustentam tal sistema são coletados de todo tipo de contribuinte, inclusive aqueles que não têm filhos 
em idade escolar ou que simplesmente os que não os possuem. Desta forma, apesar de ser um investimento público de difícil mensuração, a educação é marcada por grande responsabilidade em equalizar possíveis distorções sociais.

Segundo, o sistema educacional é o maior empregador de mão de obra com elevado grau de educação formal: os professores, pela natureza da profissão e pelo custo da formação, são o elemento mais caro do sistema de ensino. A necessidade básica da formação de professores que possibilitem a formação de outras profissões com grande lastro de especialização faz com que os sistemas de ensino sejam atrativos aos profissionais com maior escolarização, caracterizando com mais nitidez na educação superior.

O terceiro fator, no qual a maioria dos governos crê que haja relacionamento entre uma população escolarizada e crescimento econômico dos países na chamada "Era do Conhecimento": embora não haja correlação significativa em estudos empíricos, criouse como uma forte e eloquente afirmação que a escolarização plena de uma parcela significativa da população de determinado país tende a induzir o desenvolvimento econômico. Entretanto, não se tem a certeza que um empregado altamente escolarizado que executa tarefas simples em uma fábrica pode significar aumento de produção para aquela devido exclusivamente sua maior escolarização.

Pode-se caracterizar que os fatores acima respaldam-se em um mecanismo de cálculo que visa à forma ótima para a tomada de decisão. Ao racionalizar se aquilo que é investido em educação apresentará resultado positivo, a matriz utilizada para tal ignora diversas variáveis que constituem o fazer educativo, reduzindo-a apenas ao possível retorno do investimento coletivo em maior taxa de crescimento e de maiores valores de tributos a serem recolhidos.

Igualmente, quando se eleva a educação como fator primordial para o desenvolvimento de um país não observando a intrincada dinâmica de um modo de produção que está em constante processo de crises econômicas que possuem caráter metabólico (MÉSZÁROS, 2011) e que favorecem ao processo de centralização e concentração de capital. Nega-se a luta de classes em curso e responsabiliza-se o cidadão daquele país por este último não gozar de taxas satisfatórias de crescimento, mesmo este não sendo um dos protagonistas do capitalismo global.

Imputar responsabilidade fundamental à educação para o crescimento econômico, ignorando cenários constituídos historicamente, é uma das formas de fragmentar a consciência e a unidade das "classes trabalhadoras". O capital precisa de subterfúgios discursivos para dispersar atenção dos elementos realmente fundantes da dinâmica do modo de produção capitalista.

Em síntese, a Economia da Educação, ao utilizar-se da racionalidade instrumental para seu desenvolvimento teórico, se apresenta como arcabouço de justificação do cenário estabelecido historicamente e reforça aparatos discursivos que fragmentam e dispersam a classe trabalhadora de elementos realmente fundantes no processo de exploração. A 
justificativa a partir de uma retórica lógico-matemática confere a cientificidade da qual o discurso necessita e transfere para elementos secundários a responsabilidade pela equalização das injustiças advindas da dinâmica do modo de produção.

\section{A formação humana instrumental}

Ao tratarmos os dados dos documentos oficiais do Instituto Federal de Ciência e Tecnologia do Piauí (IFPI - Parnaíba), deparamo-nos com um considerável espectro instrumental na matriz de formulação de tais documentos. Ao levantarmos as passagens que eram mais representativas para efeito de formulação de um conceito que representasse a matriz instrumental para a formação humana, vislumbramos três aspectos que marcavam a influência instrumental: "o mercado e seus serviços"; "a política pública de desenvolvimento"; e "o empreendedorismo e formação humana instrumental".

\section{Mercado e seus serviços}

A maior vinculação com a matriz instrumental para a formação humana está diretamente ligada ao aperfeiçoamento do mercado capitalista e seus serviços. A formação humana se mostra como formação de trabalhadores e esse é o principal objetivo do IFPI - Campus Parnaíba.

A educação escolar responde ao projeto do capital, embora com concessões e apropriações das agendas de luta da classe trabalhadora. Mesmo incorporando conceitos e bandeiras de luta da classe dominada, a escola formal é burguesa em concepção e processos e, por isso, a massificação da razão instrumental imposta à formação humana fica evidente na análise dos projetos pedagógicos dos cursos do IFPI - Campus Parnaíba. O projeto do curso Técnico de Nível Médio em Edificações expõe nitidamente isso e logo em sua justificativa aponta que: "Nesta perspectiva, o IFPI propõe-se a oferecer o curso Técnico de Nível Médio em Edificações, na forma integrada, presencial, por entender que estará contribuindo para a elevação da qualidade dos serviços prestados à sociedade" (IFPI. p.5. 2015a).

Com este trecho, temos indícios que a maior motivação do curso não é a educação tida como transformadora ou que tem o trabalho como princípio educativo, mas a otimização e o melhoramento das estruturas do capitalismo, mesmo que a "qualidade dos serviços prestados à sociedade" seja uma expressão vaga e que pode remeter até mesmo à transformação da sociedade, o que não cremos.

Percebemos com a leitura do documento uma constante preocupação com a melhoria do mercado e seus serviços. A preocupação com a performance e com o funcionamento das organizações de mercado é posto como marco referencial de desempenho do curso, sendo clara a ligação da arquitetura do curso com as exigências do 
"mercado". No trecho a seguir destacamos mais uma vez que o papel do curso se vincula ao mercado e não à formação para a vida em sociedade ou mesmo o desenvolvimento amplo da mesma, conforme os dados do mesmo documento:

Preparar profissionais Técnicos de Nível Médio em Edificações, com conhecimento técnico-científico inerente às exigibilidades de um mercado globalizado e em permanente estado de transformação, capazes de contribuírem para o desenvolvimento da sociedade, por meio de uma contribuição efetiva ao crescimento dos negócios e do fortalecimento das organizações (IFPI. p. 12. 2015a).

O trecho anterior acentua, por meio da racionalidade instrumental, o entendimento que o progresso da sociedade está vinculado ao desenvolvimento do capitalismo como modo de produção. Negam-se, desta forma, outros vieses de entendimento do desenvolvimento humano, reforçando o avanço econômico como fator primordial para a definição do patamar de acrescimento social que se encontra a comunidade local e obscurecendo, assim, outros indicadores que apurariam os rumos da sociedade de forma mais integral.

Entretanto, o que nos chamou mais atenção sobre a preocupação com a serventia do curso para o desenvolvimento do mercado e seus serviços foi a preocupação por parte dos formuladores em traçar um perfil desejoso pelos empresários que explorariam a mão de obra egressa daquele Instituto Federal. Segue o trecho e os destaques:

No auscultamento do empresariado, procurou-se identificar, através de diversos depoimentos pessoais, o novo perfil técnico do profissional a ser edificado, enfatizando aspectos comportamentais, carências e exigibilidades do mercado, experiência já realizadas com técnicos oriundos do IFPI; tudo isso com o propósito de ofertar um curso adequado à realidade do mercado (IFPI. p. 8. 2015a).

Neste excerto fica evidente o cenário que é desenhado por um pensamento marcantemente instrumental quando aplicado às organizações escolares. Sem nenhum tipo de censura ou dissimulação, os formuladores do Projeto Pedagógico do Curso Técnico de Nível Médio em Edificações mostram que o objetivo da existência do curso é atender ao chamado do mercado e a ele ofertar mão de obra qualificada e explorável, sendo que num futuro breve a existência de tal curso represente a constituição de um vasto exército de mão de obra de reserva, visto que a dinâmica econômica de Parnaíba e região não comporta o recebimento de muitos profissionais com o perfil exigido pelas empresas.

Sendo assim, percebemos que a matriz instrumental está a serviço do desenvolvimento do capitalismo, reforçando os princípios de cálculo, fins, êxito, desempenho, utilidade e rentabilidade que compõem nossa matriz de análise para a racionalidade da formação humana instrumental. Podemos assim caracterizar que, pelos elementos levantados, o mercado é abastecido e nutrido por uma série de ações que visam ao seu aperfeiçoamento e negligenciam outros que podem ser relevantes para a formação do jovem trabalhador. Seguimos a análise mostrando que há uma vinculação com uma política de desenvolvimento que é norteada por uma transferência de responsabilidades. 


\section{A POLÍTICA PÚBLICA DE DESENVOLVIMENTO}

A escola do capitalismo está a serviço do próprio capitalismo. Apesar de ser uma redundância discursiva, apenas mostra que, mesmo existindo concessões às lutas da classe trabalhadora, o sistema escolar implementado tem a função de ser um agente potencializador do desenvolvimento do capital. Esse desenvolvimento por vezes se baseia em novos comportamentos ou entendimentos sobre o próprio conceito e processo de desenvolvimento.

Ao atentarmos para a justificativa de efetivação do curso médio de Edificações, vimos que a escuta ao empresariado local se deu com objetivo de formular um perfil desejado pelo "mercado". Outra justificativa que se soma a um pensamento utilitário da formação humana é o atendimento das políticas de desenvolvimento do Estado do Piauí, principalmente no que diz respeito ao desenvolvimento econômico. Segue o trecho que mostra uma vinculação utilitária à formação humana: Uma outra razão da existência do curso é que, pelos indicadores do SINDUSCOM, existe um número muito baixo de contratações de profissionais qualificados na área de construção civil para atender as projeções de desenvolvimento do Estado (p. 8. 2015a).

Ao "atender as projeções de desenvolvimento do Estado", os formuladores do projeto pedagógico foram parciais ao enfocar o desenvolvimento apenas vinculado ao atendimento das demandas do "mercado". Ao ser um fornecedor de mão de obra, a escola, em especial o IFPI, assume o papel de reproduzir as estruturas que sustentam o modelo de produção vigente, principalmente no reforço do exército de mão de obra de reserva.

A abundante oferta de mão de obra acaba favorecendo os contratantes que, atentos aos preceitos de Adam Smith (2010), operacionalizam uma espécie de leilão reverso para a contratação da mão da obra. A lei da oferta e da procura baixa os salários ou os benefícios dos trabalhadores, amparada pelo grande número de trabalhadores desempregados ou em empregos precários. $O$ trecho a seguir alegoriza o entendimento corrente que o desenvolvimento de uma localidade não apenas se restringe à política pública de desenvolvimento, mas que o desenvolvimento econômico passa por um processo de responsabilização individual.

\footnotetext{
Criar condições objetivas para o reconhecimento da importância da informática pelos profissionais formados no curso Técnico de Nível Médio em informática - na forma integrada do IFPI, como mecanismo de alavancar o desenvolvimento socioeconômico, em especial, na geração de emprego e renda (p. 10. 2015b).
}

O trecho mostra que, para o desenvolvimento ocorrer, é necessária uma mudança de perspectiva por parte dos jovens trabalhadores. Eles devem crer que apenas por seus esforços e vontades podem ser agentes de desenvolvimento da localidade na qual residem. Entretanto, o processo de precarização do trabalho que está em curso, local e mundialmente, vincula-se, principalmente, à transferência de responsabilidades. Desloca-se do processo de centralização e concentração de capital para as condutas individuais baseadas em uma 
noção de meritocracia. Assim, os trabalhadores, por vezes, submetem-se a esquemas de exploração de sua mão de obra esperançosos pela recompensa do seu esforço pessoal.

O processo articulado, entre a formação humana que valoriza o comportamento individual sobre o resultado do percurso de formação e a precarização dos postos de trabalho que se desenrola local e globalmente, colabora com a fragmentação da classe trabalhadora, pois este processo acirra a concorrência no interior da classe e os força a investir em cada vez mais formação, que, preferencialmente, tem caráter instrumental e que reforçaria a Teoria do Capital Humano, mas que por outro polo transforma os outros trabalhadores em concorrentes por recursos escassos, que, na conjuntura atual do capitalismo, são os melhores postos de empregos ou trabalhos, na atual conjuntura de flexibilização de direitos sociais.

Assim, mesmo os documentos oficiais do IFPI - Campus Parnaíba se mostrarem atentos às demandas levantadas pelos movimentos de desenvolvimento do capitalismo, estes documentos se direcionam à formação de trabalhadores com pouco senso de coletividade ou solidariedade entre a classe, estimulando um sentido de empreendedorismo que isola a classe, mas que cria uma massa útil, principalmente em economias baseadas em serviços como a de Parnaíba.

Sendo assim, nosso próximo subitem versará sobre a noção empregada de empreendedorismo vista nos documentos e seu desdobramento sobre a visão de utilidade posta à formação humana.

\section{Empreendedorismo e formação humana instrumental}

Nosso entendimento é que o empreendedorismo é um desdobramento do capital humano no contexto do capitalismo flexível, visto que a chamada educação empreendedora se insere na rede de ensino formal, como ao mesmo tempo monta um sistema de ensino paralelo, mas que está validado pelo sistema oficial. Vemos os casos dos cursos ofertados pelo Sistema $\mathrm{S}$ que, mesmo sob financiamento público, cobram valores elevados por cada curso e encontram público garantido sob as mesmas bases do investimento individual em educação que foi fundado pela Teoria do Capital Humano.

No caso de nossa pesquisa, vemos que a inserção da educação empreendedora no currículo do IFPI - Campus Parnaíba é um movimento orquestrado pelos setores produtivos e movimentos do terceiro setor ligados aos primeiros, que garantiu que a educação empreendedora fosse posta como componente curricular no ensino médio e superior em diversos cursos. Mas, para isso, segue-se um discurso que legitima o empreendedorismo como comportamento adequado da vida em sociedade, mas que na realidade se ocupa com as demandas do capitalismo flexível e a destruição do emprego formal. 
O projeto pedagógico do IFPI-Campus Parnaíba entende que: "Empreendedorismo - objetivando desenvolver atividades que possibilitem ao educando a aquisição de atitudes empreendedoras com a própria vida e com as oportunidades oferecidas pela sociedade" (IFPI. p. 23. 2009). Mesmo com um discurso vago, percebemos que a base da educação empreendedora é construir um comportamento aceitável para o desenvolvimento do capital, visto que percebemos um acento sobre a responsabilização individual pelos resultados do esforço do aluno.

A transferência de responsabilidade é um processo que nutre a concorrência no interior da classe trabalhadora, criando várias frações de classe no interior da mesma. Cria-se a consciência de que cada um é responsável apenas por si num safári do capital, sendo os trabalhadores responsáveis, no capitalismo flexível, por seu percurso de formação, por seu aprimoramento e até por sua "empregabilidade". Temos dentro do Projeto Pedagógico do curso de Edificações um trecho muito interessante para alegorizar este processo aqui analisado. Segue:

Criar condições objetivas para o reconhecimento da importância do empreendedorismo pelos profissionais formados no Curso Técnico de Nível Médio em Edificações - na forma integrada do IFPI, como mecanismo de alavancar o desenvolvimento socioeconômico, em especial, na geração de emprego e renda (IFPI. p. 12. 2015a).

Visto isso, percebemos que o processo de transferência de responsabilidade é a tônica da nova matriz da Teoria do Capital Humano situada no contexto do capitalismo flexível, sendo que a formação individual conduz o trabalhador às "melhores oportunidades do mercado de trabalho". Entretanto, o lado obscuro desse processo está na flexibilização das relações de trabalho e na consequente diminuição dos postos formais de trabalho.

Destarte, a escola e o sistema educacional se ocupam de tentarem conferir maior conformidade às novas demandas do capital, a partir da estimulação de novos conceitos e comportamentos que melhor se adéquem ao contexto atual. A estimulação ao maior acúmulo de conhecimentos e consequente utilização em trabalhos que não atendem mais pela estabilidade de vínculos ou legislações mais rigorosas tem como objetivo formar uma massa que se entenda "livre" e "desbravadora", mas que se encontra distanciada dos próprios semelhantes, enfraquecendo assim o sentimento de pertencimento de classe.

Assim o caráter instrumental da escola do capitalismo reside em propiciar uma formação humana voltada para o trabalho e para o empobrecimento das relações humanas e do repertório cultural acumulado historicamente. Destacamos que essa noção instrumental está mais latente nas escolas destinadas à classe trabalhadora, pois a formação de um exército de reserva deve ter por base os jovens filhos da classe trabalhadora.

Dessa forma, entendemos que a formação humana instrumental justifica a existência da escola do capitalismo, visto que por muitas vezes as ações são justificadas por um atendimento às demandas do mercado, atrelamento das ações às políticas de 
desenvolvimento estritamente ligadas ao desenvolvimento econômico e à instalação do comportamento empreendedor com viés empresarial.

\section{Conclusão}

Neste texto, buscamos caracterizar os currículos dos cursos do ensino médio integrado à educação profissional a partir da racionalidade intrumental manifesta na proposta de formação humana. Com tal proposição alcançada, mediante o estudo realizado, podemos afiançar considerações importantes dos dados investigados: a escola é um intenso movimento de assimilação e resistência frente ao projeto capitalista de formação humana e no IFPI - Campus Parnaíba a racionalidade instrumental manifesta nos documentos oficiais tenciona a formação humana para um padrão de reprodução dos mecanismos de adaptação do processo educativo, que de uma forma tende a uma formação parcializada pelo próprio projeto do capital.

Embora tenhamos verificado que a escola se caracterize por ser um ambiente de disputas típico da luta de classes, visto que vários projetos de sociedade e de homem disputam a hegemonia da circulação de ideias no meio escolar, o mercado ainda é o grande vencedor, principalmente por se tratar de uma instituição de educação profissional.

O tensionamento proeminente existente naquele espaço favorece ao mercado, pois com o empobrecimento do espaço de aprendizagem pode, assim, lançar mão de outros produtos e serviços para sanar as falhas na formação ofertada, uma vez que a escola, com objetivo de formar o cidadão consciente, crítico, humano, cidadão e trabalhador, certamente encontrará obstáculos para a consecução de tantas características postas como desejáveis.

Portanto, o alinhamento dos projetos pedagógicos dos cursos e do projeto político pedagógico do próprio Instituto aos fundamentos da Teoria do Capital Humano e seus desdobramentos marca a primazia pela racionalidade instrumental e, estritamente, um projeto de sociedade desejada pelos detentores do poder econômico e político. A expropriação da classe trabalhadora do acesso de uma educação "multirracional", em que diversos saberes são valorizados, potencializa o processo de formação de "recursos humanos" para os empreendimentos capitalistas.

Atrelemos ao exposto anteriormente a noção de responsabilidade individual pelo próprio desenvolvimento do capitalismo e das economias regionais e locais. Fragmentar a classe trabalhadora em portadores de capital humano e, por isso, potenciais empreendedores, acirra a concorrência no interior da classe por recursos a ela escassos, gerando uma competição generalizada entre aqueles que estão mais ajustados contra os menos ajustados às dinâmicas do capital.

Consideramos que a pesquisa aqui apresentada possui uma limitação no que concerne centralizar sua análise restritamente aos documentos de referências da organização escolar formal. De outro lado, baseados nos mesmos documentos, vemos 
que a escola, mesmo absorvendo o corolário que justifica o processo de exploração capitalista, resiste no sentido contrário em um processo dialético que muitas vezes nega a assimilação total da primazia da lógica racional instrumental e dos fundamentos da Teoria do Capital Humano. Por isso, entendemos que próximas pesquisas focalizem o processo de tensionamento existente no processo de reprodução-enfrentamento da ideologia do capital no interior do fazer educativo escolar.

Entendemos que os próprios documentos que norteavam o fazer pedagógico do IFPI - Campus Parnaíba mostravam que a escola é, de fato, uma arena de disputas que está em constante movimento em busca de uma homeostase que lhe ajuste ao sistema ou que trace movimentos de transformação caótica, os quais signifiquem uma remodelação das dinâmicas de exploração ou até mesmo um processo de desestruturação do atual modelo, forçando uma remodelação da sociedade.

\section{Referências}

BOWLES, S.; GINTIS, H. El problema de la teoria del capital humano: una crítica marxista. Revista de Economía Crítica, nº18, segundo semestre 2014, ISNN 2013-5254.

CARNOY, M. Economia de la educacion. Barcelona: Editora UOC, 2006.

GUERREIRO RAMOS, A. A Nova Ciência das Organizações. Uma reconceituação da riqueza nas nações. Rio de Janeiro, Fundação Getúlio Vargas, 1981.

IFPI. Projeto político-pedagógico - campus Parnaíba. Parnaíba: IFPI, 2009.

IPFI. Projeto pedagógico do curso técnico de nível médio em edificações na forma integrada. Teresina: IFPI, 2015a.

IFPI, Projeto pedagógico do curso técnico de nível médio em eletrotécnica na forma integrada. Teresina: IFPI, 2015b.

MARX, K. O Capital - crítica da economia política. Livro I: o processo de produção do capital. São Paulo: Boitempo, 2013.

MÉSZÁROS, I. A crise estrutural do capital. São Paulo: Boitempo, 2011.

MOTTA, F. C. P. Teoria das Organizações: evolução e crítica. São Paulo: Pioneira Thomson Learning, 2003.

SENNETT, R. A corrosão do caráter: consequências pessoais do trabalho no novo capitalismo. Rio de Janeiro: Record, 2009.

SERVA, M. A racionalidade substantiva demonstrada na prática. Revista de Administração de Empresas. São Paulo, v. 37, n. 2, abr./jun. 1997, p. 18-30.

SCHULTZ, T. W. O Capital Humano: Investimentos em Educação. São Paulo: Zahar editora, 1973. 
SMITH, A. A Riqueza das Nações. - das causas do aprimoramento das forças produtivas do trabalho e ordem segundo a qual sua produção é naturalmente distribuída entre as diversas categorias do povo. Livro I. Curitiba: Juruá, 2010.

Artigo recebido em: 07/09/2018

Aprovado em: 05/12/2018

Contato para correspondência:

Élido Santiago da Silva.E-mail: elidosantiago@gmail.com 